\title{
Dyslipidemia and associated factors among diabetic patients attending Durame General Hospital in Southern Nations, Nationalities, and People's Region
}

This article was published in the following Dove Press journal: Diabetes, Metabolic Syndrome and Obesity:Targets and Therapy 22 June 2017

Number of times this article has been viewed

\section{Shiferaw Bekele \\ Tagesech Yohannes \\ Abdurehman Eshete \\ Mohammed}

Department of Medical Laboratory Sciences, College of Health Sciences, Jimma University, Jimma, Ethiopia

Correspondence: Shiferaw Bekele Department of Medical Laboratory Sciences, College of Health Sciences, Jimma University, PO Box 378, Jimma, Ethiopia

Tel +25 I 47 III I 875

Email bekeleshiferaw@yahoo.com
Background: Diabetes mellitus is a group of metabolic disorders that are caused by deficiency in insulin secretion or the decreased ability of insulin to act effectively on target tissues, particularly muscle, liver, and fat. As a result of insulin resistance in the target tissues, particularly in the adipocytes, free fatty acid flux is increased, leading to increased lipid synthesis in hepatocytes, which is responsible for diabetic dyslipidemia.

Objective: The objective of this study was to determine the prevalence and associated factors of dyslipidemia among diabetic patients in Durame General Hospital in Kembata Tembaro zone. Methods: A cross-sectional study was conducted from September 2015 to April 2016. In total, 224 subjects were involved in the study by using convenient sampling techniques. Face-to-face interview-administered questionnaire was used to collect sociodemographic data and other possible clinical data associated with the prevalence of dyslipidemia. Fasting venous blood specimens were collected to assess serum lipid profiles. Blood pressure (BP), weight, height, and waist circumference were measured.

Results: The prevalence of dyslipidemia was $65.6 \%$. Individual lipid abnormality of elevated LDL-C, TC, TG, and reduced HDL-C were identified in $43.8 \%, 23.7 \%, 40.6 \%$, and $41.9 \%$ of study subjects, respectively. The prevalence of dyslipidemia was significantly associated with high BP, high body mass index, aging, and longer duration of diabetes mellitus.

Conclusion: High prevalence of dyslipidemia was found among diabetic patients in the study area. Therefore, a compressive mechanism is required to screen, treat, and prevent dyslipidemia. Keywords: diabetes, lipid profile, Jimma, Ethiopia

\section{Introduction}

Diabetes mellitus is a progressive chronic disease caused by a relative or definite insulin deficiency or by insulin resistance, leading to hyperglycemia that is characterized by metabolic disorders of lipids, carbohydrates, and proteins. ${ }^{1-3}$ The decreased ability of insulin to act effectively on target tissues leads to metabolic abnormalities that cause an increased risk of cardiovascular disease (CVD) and diabetes mellitus (DM). The important features of the insulin resistance include central obesity, hypertriglyceridemia, low high-density lipoprotein (HDL) cholesterol, hyperglycemia, and hypertension. ${ }^{4-6}$ An early major contributor to the development of insulin resistance is overabundance of circulating free fatty acids (FFAs) that are released from expanded adipose tissue triglyceride (TG) stores through the lipolysis of TG-rich lipoproteins in tissues by lipoprotein lipase. ${ }^{7-9}$ 
In the liver, FFAs result in an increased production of glucose and TGs, secretion of very low-density lipoprotein cholesterol (VLDL-C) and low-density lipoprotein cholesterol (LDL-C), as well as reduction in HDL cholesterol (HDL-C). ${ }^{4}$ FFAs also reduce insulin sensitivity in muscle by inhibiting insulinmediated glucose uptake, and FFA flux to the liver is associated with the increased production of TG-rich VLDL-C. ${ }^{10-12}$

Dyslipidemia can be defined as lipid metabolism disorder that can lead to elevated total or LDL-C levels or low levels of HDL-C. Diabetic dyslipidemia is a cluster of plasma lipid and lipoprotein abnormality that is metabolically interrelated, and it is characterized by low HDL-C and increased LDL-C, TGs, and total cholesterol (TC) levels. The pattern of abnormality lipoproteins can be individual or combined. High levels of TGs or low levels of HDL-C or both have been identified in approximately half of the subjects in type 2 DM (T2DM). The abnormal features of the lipid profile are common in subjects with central obesity, metabolic syndrome, insulin resistance, and T2DM. ${ }^{13,14}$

Dyslipidemia is the most important and modifiable risk factor for CVDs. Atherogenic dyslipidemia is one of the major risk factors for CVD in diabetic patients. An increase level of VLDL particles in T2DM leads to the generation of atherogenic remnants. Type 1 diabetes (T1D) is also associated with high CVD risk. The lipid profile in T1D with good glycemic control is characterized by subnormal TG and LDL-C, but with slightly elevated HDL-C. ${ }^{15-17}$

The prevalence of dyslipidemia is continuously increasing globally probably due to Westernization of diet, reduced physical activity, and urbanization as well as obesity. Physical inactivity or sedentary lifestyle is a predictor of CVD events and related mortality. Increased adipose tissue (predominantly central), reduced HDL-C, increased TGs, high blood pressure (BP), and high blood glucose concentration are associated with a sedentary lifestyle. ${ }^{18-20}$ There is also high prevalence of dyslipidemia in developing countries due to urbanization, changing lifestyle, and food habits. There are very few data available on the prevalence of dyslipidemia in diabetic patients in Ethiopia. As to the knowledge of the principal investigators, there are no data available on the prevalence of dyslipidemia among diabetic patients in the study area. Therefore, the present study aimed at studying the prevalence, severity, and pattern of dyslipidemia among diabetic subjects in the study area.

\section{Materials and methods}

The study was conducted in Southern Nations, Nationalities, and People's Region at Durame Hospital, Kembata Tembaro zone, which is located $290 \mathrm{~km}$ away to the south from Addis Ababa, capital of Ethiopia. The Kembata Tembaro zone has a total population of 828,002 , of which 404,150 (48.81\%) and 423,852 (51.19\%) are women and men, respectively. The study was conducted from September 2015 to April 2016. This is an institution-based cross-sectional study.

\section{Data collection techniques}

Before collecting any data, an ethical clearance was obtained from the ethical review board of Institute of Health Sciences, Jimma University, to Durame Hospital medical authorities. Next, a permission letter was obtained from the medical director of Durame Hospital to diabetic clinic head office to conduct the study. Then, the aim of the study was clearly explained to the study subjects. A convenient sampling technique was used to select study subjects from study population; this sampling technique was used because it was difficult to use random sampling technique as the study subjects' appointment for their follow-up varied, and some of them might not come for the follow-up on the specified date. In addition to this, it is easy and not time-consuming compared to other sampling techniques. A written consent was obtained from each study subject before any data collection. Interview-administered structured questionnaire was used to collect sociodemographic and clinical data. Those study subjects who were pregnant; who were taking lipid lowering drugs; and who had a known history of cardiac problem, chronic liver, and renal diseases were excluded from the study.

\section{Physical examination}

Anthropometric measurements were administered by trained professional nurses working at diabetic clinic in the morning after overnight fasting by using a standardized protocol. The height and weight of each study subject were measured by using analog digital scale without shoes. The height was measured by instructing each subject's feet pointed outward; legs straight and knee together; arms at sides; head, shoulder blades, buttocks, and heels touching measurement surface; looking straight ahead; and shoulder relaxed. The body mass index (BMI) was calculated by using the formula, weight over height square, and the results were recorded.

Circumferences were evaluated by using a stretch-resistant 1-cm-wide measuring tape that provides a constant measurement. Circumference measurements were taken while the subject is in the standing position and breathing normally.

Hip circumference was measured around the widest portion of the buttocks, with the tape parallel to the floor. For taking both waist and hip circumference measurements, the 
tape was snug around the body, but not pulled so tight that it is constricting. Each measurement was repeated twice; the average of measurements within $1 \mathrm{~cm}$ of one another was calculated. If the difference between the two measurements exceeds $1 \mathrm{~cm}$, the two measurements were repeated.

Waist-to-hip ratio (WHR) was calculated as indicated by World Health Organization as waist circumference (WC) divided by hip circumference. The normal range for WC is $\leq 120 \mathrm{~cm}$ for men and $\leq 88 \mathrm{~cm}$ for women, and the normal range for WHR is 0.9 for men and 0.85 for women. BP was measured by using a mercury sphygmomanometer for three consecutive times. The first measurement was taken after a person sits down for at least 10 minutes, and the following measurements were taken every 5 minutes thereafter. The $\mathrm{BP}$ values used for analysis were the mean of the last two measurements.

\section{Blood specimen collection technique and investigation}

Five milliliter blood was collected from each study subject by a trained medical laboratory technologist after overnight fasting following the standard operating procedure guideline. The collected blood specimen was kept at room temperature for $\sim 30$ minutes for clot formation. After clot formation, the blood was centrifuged at 2,000 rpm for 10 minutes by using a fixed head rotor centrifuge. Then, the serum was separated from the whole blood and stored at $-20^{\circ} \mathrm{C}$ before analysis. Then, the analysis was performed by using A25 BioSystems clinical chemistry analyzer (BioSystems, Costa Brava, Spain) at Hawassa University Referral Hospital Laboratory Unit.

\section{Definition of terms}

Hypertension was defined as systolic BP (SBP; $\geq 140$ millimeter of mercury $[\mathrm{mmHg}]$ ) or diastolic BP (DBP; $\geq 90$ $\mathrm{mmHg}$ ); both SBP and DBP are elevated in patients on antihypertensive medication.

Dyslipidemia was defined as lipid profile that consists of the following abnormalities either singly or in combination. These include TC $\geq 200 \mathrm{mg} / \mathrm{dL}$, TG levels $\geq 150 \mathrm{mg} / \mathrm{dL}$, HDL-C $<40 \mathrm{mg} / \mathrm{dL}$, and LDL-C $\geq 100 \mathrm{mg} / \mathrm{dL}$.

Based on the results of BMI, study subjects were categorized as underweight with BMI $<18.5 \mathrm{~kg} / \mathrm{m}^{2}$; normal weight when BMI range was 18.5 to $24.9 \mathrm{~kg} / \mathrm{m}^{2}$; overweight with BMI range from 25 to $29.9 \mathrm{~kg} / \mathrm{m}^{2}$; obese with BMI range from 30 to $34.9 \mathrm{~kg} / \mathrm{m}^{2}$; severely obese with BMI range from 35 to $39.9 \mathrm{~kg} / \mathrm{m}^{2}$; and morbidly obese with BMI range $\geq 40 \mathrm{~kg} / \mathrm{m}^{2}$.

\section{Statistical analysis}

Statistical analysis of the data was performed by using Microsoft Office Excel for Windows 2008 and SPSS Version 20.0 software. Bivariate and multivariate logistic regression models were used to assess how well predictor independent variables explain or predict dependent variables and to control possible confounders and to identify the determinant factors associated with the prevalence of dyslipidemia. $P$-value $<0.05$ was considered as statistically significant. All the data from questionnaires were checked manually for completeness and clarity as well as edited for inconsistencies before data analysis.

\section{Results \\ Sociodemographic and other characteristics of study subjects}

From the 224 study subjects involved in the study, $53.6 \%$ of them $(n=120)$ were men, and the rest were women; the mean age was $38 \pm 15$; the majority of the study subjects $(66.5 \%$; $\mathrm{n}=149)$ were aged $>30$ years; $59.8 \%(\mathrm{n}=134)$ of them were urban dwellers; and $40.6 \%(n=91)$ of them had attended their secondary education. The prevalence of dyslipidemia was highest among men $(38.8 \% ; n=84)$, and among agegroups $>30$ years $(43.8 \% ; n=98)$. Again the prevalence of dyslipidemia was highest among urban dwellers (36.2\%; $\mathrm{n}=81)$ compared to rural dwellers. From $24.1 \%(\mathrm{n}=54)$ of the study subjects who were overweight according to BMI calculation, $94.4 \%(n=51)$ of them had abnormal serum lipid profile, whereas $26.3 \%(n=59)$ of them had abnormal serum lipid profile according to WHR. From $6.7 \%(n=15)$ of the study subjects who were obese according to BMI calculation, $93.3 \%(n=14)$ of them had abnormal lipid profile, whereas $80.0 \%(n=64)$ of 80 obese individuals had abnormal lipid profile according to WHR (Table 1).

\section{Pattern of serum lipid profile abnormality and prevalence of dyslipidemia components}

The pattern of serum lipid abnormality was identified. According to this pattern, $\sim 26.5 \%(n=39)$ of study subjects from $65.6 \%(n=147)$ had single or isolated lipid profile abnormality, whereas $73.5 \%(n=108)$ of the subjects had combined serum lipid abnormality. From isolated or individual lipid abnormality, LDL-C was found among $6.7 \%(n=15)$ of the subjects, whereas HDL-C, LDL-C, TG, and TC were the combined lipid profile abnormality found among $11.2 \%$ $(n=25)$ from total 147 study subjects identified with lipid 
Table I Sociodemographic and other characteristics of study subjects

\begin{tabular}{|c|c|c|c|c|}
\hline \multirow[t]{2}{*}{ Variables } & \multirow[t]{2}{*}{ Category } & \multirow[t]{2}{*}{ n (\%) } & \multicolumn{2}{|c|}{ Dyslipidemia } \\
\hline & & & Yes (\%) & No (\%) \\
\hline \multirow[t]{2}{*}{ Sex } & Male & $120(53.6)$ & $84(38.8)$ & $36(0.2)$ \\
\hline & Female & $104(46.4)$ & $63(16.1)$ & $4 \mid(18.3)$ \\
\hline \multirow[t]{2}{*}{ Age } & $<30$ years & $75(33.5)$ & $49(21.9)$ & $26(11.6)$ \\
\hline & $>30$ years & $149(66.5)$ & $98(43.8)$ & $5 \mathrm{I}(22.8)$ \\
\hline \multirow[t]{2}{*}{ Residence } & Urban & I34 (59.8) & 81 (36.2) & $53(23.7)$ \\
\hline & Rural & $90(40.2)$ & $66(29.5)$ & $24(10.7)$ \\
\hline \multirow[t]{6}{*}{ Occupation } & Merchant & $29(12.9)$ & $13(5.8)$ & $16(7.1)$ \\
\hline & Farmer & $47(20.9)$ & $35(15.6)$ & $12(5.4)$ \\
\hline & Employee & $56(25.0)$ & $32(14.3)$ & $24(10.7)$ \\
\hline & Housewife & $48(2 \mid .4)$ & $41(18.3)$ & $7(3.1)$ \\
\hline & Student & $2(0.9)$ & I (0.4) & I $(0.4)$ \\
\hline & Daily labor & $42(18.8)$ & $25(11.2)$ & $17(7.6)$ \\
\hline \multirow[t]{5}{*}{ Educational status } & Illiterate & $48(21.4)$ & $36(16.1)$ & $12(5.4)$ \\
\hline & Able to read and write & $4(1.8)$ & $2(0.9)$ & $2(0.9)$ \\
\hline & Primary education & $40(17.9)$ & $32(14.3)$ & $8(3.6)$ \\
\hline & Secondary education & $91(40.6)$ & $50(22.3)$ & $4 \mid(18.3)$ \\
\hline & College and above & $4 \mid(18.3)$ & $27(12.1)$ & $14(6.3)$ \\
\hline \multirow[t]{2}{*}{ Mode of transport } & On foot & $191(85.3)$ & $145(64.7)$ & $46(28.1)$ \\
\hline & Public vehicle & $33(14.7)$ & $2(0.9)$ & $3 \mid(\mid 3.8)$ \\
\hline \multirow[t]{4}{*}{ BMI } & Underweight & $25(11.2)$ & $16(7.1)$ & $9(4.0)$ \\
\hline & Normal weight & $130(58.0)$ & $66(29.5)$ & $64(28.6)$ \\
\hline & Overweight & $54(24.1)$ & $51(22.8)$ & $3(1.3)$ \\
\hline & Obese & $15(6.7)$ & $14(6.3)$ & I (0.4) \\
\hline \multirow[t]{3}{*}{ WHR } & Normal & $65(29.0)$ & $24(10.7)$ & $4 \mid(18.3)$ \\
\hline & Overweight & $79(35.3)$ & $59(26.3)$ & $20(8.9)$ \\
\hline & Obese & $80(35.7)$ & $64(28.6)$ & $16(7.1)$ \\
\hline \multirow[t]{2}{*}{ Hypertension } & Yes & $73(32.6)$ & $50(22.3)$ & $23(10.3)$ \\
\hline & No & 151 (67.4) & $97(43.3)$ & $54(24.1)$ \\
\hline \multirow[t]{2}{*}{ Family history of DM } & Yes & $36(16.1)$ & $23(10.3)$ & $13(5.8)$ \\
\hline & No & $188(83.9)$ & $124(55.4)$ & $64(28.6)$ \\
\hline \multirow[t]{3}{*}{ Duration of DM } & $<6$ years & $139(62.1)$ & $99(44.2)$ & $40(17.9)$ \\
\hline & $6-10$ years & $58(64.3)$ & $37(16.5)$ & $21(9.4)$ \\
\hline & $>10$ years & $27(12.1)$ & II (4.9) & $16(7.1)$ \\
\hline
\end{tabular}

Abbreviations: BMI, body mass index; DM, diabetes mellitus; WHR, waist-to-hip ratio.

abnormality. When dyslipidemia components were analyzed, hypercholesterolemia was found in $23.7 \%(n=53)$, hypertriglyceridemia in $40.6 \%(n=91)$, high level of LDL-C in $43.8 \%$ $(n=98)$, and low level of HDL-C in 41.9\% ( $n=94$; Table 2).

\section{Factors associated with the prevalence of dyslipidemia}

Ten independent variables were entered to multivariate logistic regression analysis model to identify independent predicator variable that was associated with the prevalence of dyslipidemia. According to this analysis, being female, aged $>30$ years, being overweight, obesity, hypertension, mode of transport, and having 6-10 and $>10$ years of diabetes had statistically significant association with the prevalence of dyslipidemia $(P<0.05)$. In contrast, residence, educational status, and family history of DM had no statistically significant association with the prevalence of
Table 2 Pattern of lipid abnormality among study subjects

\begin{tabular}{lll}
\hline Lipid abnormality & & $\mathbf{n}(\%)$ \\
\hline Isolated & Low HDL-C & $14(6.3)$ \\
& High TC & $\mathrm{I}(0.4)$ \\
& High LDL-C & $15(6.7)$ \\
Combined & High TG & $9(4.0)$ \\
& HDL-C and LDL-C & $12(5.4)$ \\
& HDL-C and TG & $24(10.7)$ \\
& HDL-C, LDL-C, and TG & $13(5.8)$ \\
& HD-C, LD-C, and TC & $6(2.7)$ \\
& LDL-C and TC & $8(3.6)$ \\
& LDL-C and TG & $7(3.1)$ \\
& TG and TC & $1(0.4)$ \\
& LDL-C, TC, and TG & $12(5.4)$ \\
& HDL-C, LDL-C, TG, and TC & $25(11.2)$ \\
Combined plus isolated & Low HDL-C & $94(41.9)$ \\
& High TG & $91(40.6)$ \\
& High LDL-C & $98(43.8)$ \\
& High TC & $53(23.7)$ \\
\hline
\end{tabular}

Abbreviations: HDL-C, high-density lipoprotein cholesterol; LDL-C, low-density lipoprotein cholesterol; TC, total cholesterol; TG, triglyceride. 
dyslipidemia. Older diabetic patients were $\sim 8$ times more likely to develop dyslipidemia (adjusted odd ratio $[\mathrm{AOR}]=8$; $95 \% \mathrm{CI}=0.185-11.797$ ) than lower age-groups. Obese and overweight diabetic patients were, respectively, $\sim 12.6$ times ( $\mathrm{AOR}=12.6 ; 95 \% \mathrm{CI}=2.247-70.703$ ) and 8.09 times (AOR $=8.09 ; 95 \% \mathrm{CI}=0.720-91.092$ ) more likely to develop dyslipidemia compared to other diabetic patients. Diabetic patients who always use vehicles as a mode of transport were $\sim 14$ times more likely to develop dyslipidemia (AOR $=14 ; 95 \%$ $\mathrm{CI}=0.587-33.54$ ) compared to those who walk on foot. Diabetic patients with between 6-10 years and $>10$ years were, respectively, $\sim 8.5$ times ( $\mathrm{AOR}=8.5 ; 95 \% \mathrm{CI}=2.405-30.258$ ) and 13.8 times $(\mathrm{AOR}=13.8 ; 95 \% \mathrm{CI}=3.080-61.973)$ more likely to develop dyslipidemia compared with lower agegroups (Table 3 ).

\section{Discussion}

Due to economic growth and changing of lifestyle in developing countries, the prevalence of abnormal serum lipid profile is increasing, particularly in population with chronic illness with less physical activity. Dyslipidemia is the most important independent predictor of CVD in diabetic patients, which leads to the high morbidity and mortality of diabetic patients.
The current study was conducted to assess the prevalence of dyslipidemia and associated factors in Durame General Hospital in Kembata Tembaro zone. According to our finding, $41.9 \%, 43.8 \%, 40.6 \%$, and $23.7 \%$ were the prevalence of individual lipid profile of low HDL-C, high LDL-C, TG, and TC, respectively.

The prevalence of low HDL-C in our study is almost comparable to the finding from United Arab Emirates, whereas the prevalence of hypertriglyceridemia in our finding is much higher than that from United Arab Emirates. ${ }^{21}$ The prevalence of high-level TC in the current finding is much lower than the finding reported from Libya, but the prevalence of high TG and LDL-C is almost comparable. ${ }^{22}$ The prevalence values of hypercholesterolemia, hypertriglyceridemia, and low HDL-C and high LDL-C are much less than the finding reported from Jordan in which $77.2 \%, 83.1 \%, 83.9 \%$, and 91.5\% were the prevalence of TC, TG, low HDL-C, and high LDL-C, respectively. ${ }^{23}$

Combined prevalence of reduced HDL-C, elevated LDL-C, TG, and TC was indicated in $11.6 \%(n=26)$ of the study subjects. The study also indicated that the prevalence of dyslipidemia was $65.6 \%$. This finding is much higher compared to the study conducted in China where

Table 3 Multivariate stepwise logistic regression analysis of factors associated with dyslipidemia

\begin{tabular}{|c|c|c|c|c|c|}
\hline \multirow[t]{2}{*}{ Variables } & \multirow[t]{2}{*}{ Category } & \multicolumn{2}{|c|}{ Dyslipidemia } & \multirow[t]{2}{*}{ AOR (95\% Cl) } & \multirow[t]{2}{*}{ P-value } \\
\hline & & Yes & No & & \\
\hline \multirow[t]{2}{*}{ Sex } & Male & $84(38.8)$ & $36(0.2)$ & $\mathrm{I}$ & \\
\hline & Female & $63(16.1)$ & $41(18.3)$ & $3(0.126-1.488)$ & 0.014 \\
\hline \multirow[t]{2}{*}{ Age } & $<30$ years & $49(21.9)$ & $26(11.6)$ & I & \\
\hline & $>30$ years & $98(43.8)$ & $51(22.8)$ & $8(0.185-11.797)$ & 0.042 \\
\hline \multirow[t]{2}{*}{ Residence } & Urban & $81(36.2)$ & $53(23.7)$ & $0.546(0.268-5.670)$ & 0.134 \\
\hline & Rural & $66(29.5)$ & $24(10.7)$ & 1 & \\
\hline \multirow[t]{5}{*}{ Education status } & Illiterate & $36(16.1)$ & $12(5.4)$ & 1 & \\
\hline & Able to read and write & $2(0.9)$ & $2(0.9)$ & $0.478(0.125-12.45)$ & 0.235 \\
\hline & Primary education & $32(14.3)$ & $8(3.6)$ & $0.543(0.765-1.76)$ & 0.576 \\
\hline & Secondary education & $50(22.3)$ & $4 \mid(18.3)$ & $0.987(0.043-0.345)$ & 0.876 \\
\hline & College and above & $27(12.1)$ & $14(6.3)$ & I (0.089-|4.67) & 0.345 \\
\hline \multirow[t]{2}{*}{ Mode of transport } & On foot & $145(64.7)$ & $46(28.1)$ & $\mathrm{I}$ & \\
\hline & Public vehicle & $2(0.9)$ & $31(13.8)$ & $14(0.587-33.54)$ & 0.023 \\
\hline \multirow[t]{4}{*}{ BMI } & Underweight & $16(7.1)$ & $9(4.0)$ & 1 & \\
\hline & Normal weight & $66(29.5)$ & $64(28.6)$ & $1.279(0.445-3.673)$ & 0.648 \\
\hline & Overweight & $51(22.8)$ & $3(1.3)$ & 12.605 (2.247-70.703) & 0.004 \\
\hline & Obese & $14(6.3)$ & $\mathrm{I}(0.4)$ & 8.097 (0.720-9I.092) & 0.090 \\
\hline \multirow[t]{2}{*}{ Hypertension } & Yes & $50(22.3)$ & $23(10.3)$ & $1.331(0.436-4.062)$ & 0.016 \\
\hline & No & $97(43.3)$ & $54(24.1)$ & 1 & \\
\hline \multirow[t]{2}{*}{ Family history of DM } & Yes & $23(10.3)$ & $13(5.8)$ & 2.118 (0.454-9.877) & 0.339 \\
\hline & No & $124(55.4)$ & $64(28.6)$ & 1 & \\
\hline \multirow[t]{3}{*}{ Duration of DM } & $<6$ years & $99(44.2)$ & $40(17.9)$ & I & \\
\hline & $6-10$ years & $37(16.5)$ & $21(9.4)$ & 8.531 (2.405-30.258) & 0.001 \\
\hline & $>10$ years & II (4.9) & $16(7.1)$ & 13.816 (3.080-61.973) & 0.001 \\
\hline
\end{tabular}

Abbreviations: AOR, adjusted odd ratio; BMI, body mass index; DM, diabetes mellitus. 
the prevalence of dyslipidemia was $34.64 \%{ }^{24}$ and less than the finding reported from Jordan in which the prevalence of dyslipidemia was $90 \%$, and the prevalence was much higher among male diabetic patients compared to women in contrast to the study reported from Jordan. ${ }^{23}$ The prevalence of the current finding is also less than the finding reported from Finland and USA in which the prevalence values of dyslipidemia were $85.0 \%$ and $70.5 \%$, respectively. ${ }^{22}$ The prevalence of individual lipid profile was almost similar to a study conducted in other area of Ethiopia except that there is much higher prevalence of low HDL-C in the current study. ${ }^{25}$

Our study also revealed that being female, aged $>30$ years, being overweight, obesity, hypertension, and having 6-10 and $>10$ years diabetes were statistically associated with the prevalence of dyslipidemia.

\section{Limitation of the study}

We did not classify the study subjects as type 1 diabetics or type 2 diabetics because the diagnosis of diabetes was based only on clinical and abnormal fasting or random blood sugar, which is not used to distinct the type of diabetes.

\section{Conclusion}

Our study indicated the high prevalence of dyslipidemia among diabetic patients. Gender, aging, longer duration of diabetes, higher BMI, and high BP were the risk factors associated with the prevalence of dyslipidemia. Dyslipidemia is the major public health problem in developing countries; and it is an independent predictor factor for developing CVD. In addition, with other risk factors such as high BP, it complicates the development of CVD among diabetic patients, leading to high mortality. Therefore, it is mandatory to screen, treat, and educate diabetic patients about dyslipidemia and its associated risk factors.

\section{Acknowledgments}

We would like to thank College of Health Sciences, Jimma University, for funding this project. We would also like to thank data collectors, study participants, and supervisors as well as those directly or indirectly contributed to this study. All authors were equally involved in research work.

\section{Author contributions}

All authors contributed toward data analysis, drafting and critically revising the paper and agree to be accountable for all aspects of the work.

\section{Ethical consideration}

Ethical clearance was obtained from ethical review board of College of Health Sciences, Jimma University, to Durame Hospital Medical authorities. Next, a permission letter was obtained from medical director of Durame Hospital to diabetic clinic head office to conduct the study. Before actual data collection, the purpose of the study was explained to each study participant. The data collected from each study participant were used only for the purpose of this study. Verbal consent was obtained from each study participant, and the study participants had full right to withdraw from the study at any time.

\section{Disclosure}

The authors report no conflicts of interest in this work.

\section{References}

1. Jameson JL. Harrison's Endocrinology. 2nd ed. New York: Chicago; 2010.

2. Habib S. Frequency distribution of atherogenic dyslipidemia in Saudi type 2 diabetic patients. Pak J Physiol. 2006;2(2):20-23.

3. Mooradian A. Dyslipidemia in type 2 diabetes mellitus. Nat Clin Pract Endocrinol Metab. 2009;5(3):150-159.

4. Otamere HO, Aloamaka CP, Okokhere PO, Adisa WA. Lipid profile in diabetes mellitus; what impact has age and duration. Br J Pharmacol Toxicol. 2011;2(3):135-137.

5. Estari M, ReddyA S, Bikshapathi T, Satyanarayana J, Venkanna L, Reddy MK. The investigation of serum lipids and prevalence of dyslipidemia in urban adult population of Warangal district Andhra Pradesh, India. Biol Med. 2009;1:61-65.

6. Riethof M, Flavin PL, Lindvall B, et al. Diagnosis and Management of Type 2 Diabetes Mellitus in Adults. Bloomington (MN): Institute for Clinical Systems Improvement (ICSI); 2012:1-142.

7. Leiviskä J. Laboratory Diagnostics of Dyslipidemia. National Institute for Health and Welfare; University of Helsinki, Helsinki, 2013:1-81.

8. Huri HZ. Dyslipidemia and type 2 diabetes mellitus: implications and role of ant platelet agents in primary prevention of cardiovascular disease. In Dyslipidemia From Prevention to Treatment. InTech, online. 2012.

9. Jan SS, Khan TM, Ahmad R, Zaman S, Ahmad A. Pattern of dyslipidemia in adult diabetic subjects in the community hospital of district Swat. J Ayub Med Coll Abbottabad. 2011;23(1):106-109.

10. Mithal A, Majhi D, Shunmugavelu M, Talwarkar PG, Vasnawala H, Raza AS. Prevalence of dyslipidemia in adult Indian diabetic patients: a cross-sectional study (SOLID). Indian J Endocrinol Metab. 2014;18(5):642-647.

11. Shradha B, Sisodia SS. Diabetes, dyslipidemia, antioxidant and status of oxidative stress. Int J Res Ayurveda Pharm. 2010;1(1):33-42.

12. Solano MP, Goldberg RB. Management of dyslipidemia in diabetes. Cardiol Rev. 2006;14(3):125-135.

13. Qi Q, Liang L, Doria A, Hu FB, Qi L. Genetic predisposition to dyslipidemia and type 2 diabetes risk in two prospective cohorts. Diabetes. 2012;61:745-752.

14. Bays HE, Toth PP, Kris-Etherton PM, et al. Obesity, adiposity, and dyslipidemia: A consensus statement from the National Lipid Association. J Clin Lipidol. 2013;7(4):304-383.

15. Bello-Sani F, Bakari AG, Anumah FE. Dyslipidaemia in persons with type 2 diabetes mellitus in Kaduna, Nigeria. Int J Diabetes Metab. 2007;15:9-13. 
16. Taskinen MR. Diabetic dyslipidemia. Atheroscler Suppl. 2002;3(1): $47-51$.

17. Tamba SM, Ewane ME, Bonny A, et al. Micro and macro complication of DM in cameroon: risk factors and effect of diabetic checkup - a monocentric observational study. Pan Afr Med J. 2013;15(141): $1-10$.

18. Sawant AM, Shetty D, Mankeshwar R, Ashavaid TF. Prevalence of dyslipidemia in young adult Indian population. $J$ Assoc Physicians India. 2008;56:99-102.

19. Uttra KM, Devrajani BR, Ali Shah SZ, et al. Lipid profile of patients with diabetes mellitus. World Appl Sci J. 2011;12:1382-1384.

20. Blebil AQ, Hassan Y, Dujaili JA, Aziz NA. Pattern of dyslipidemia in type 2 diabetic patients in the state of Penang, Malaysia. Int J Pharm Sci. 2012;4:305-308.
21. Alsaadi M, Qassim S, Hamad F, Metwali Z. Pattern of dyslipidaemia in patients with type 2 diabetes mellitus in Fujairah, United Arab Emirates. Eur J Pharma Med Res. 2016;3(2):340-347.

22. Mohamed A, Zuhair G, Samir A, et al. Dyslipidemia in type 2 diabetes mellitus patients in Benghazi, Libya. IJBAR. 2015;6(10):749-753.

23. Abdel-Aal NM, Ahmad AT, Froelicher ES, Batieha AM, Hamza MM, Ajlouni KM. Prevalence of dyslipidemia in patients with type 2 diabetes in Jordan. Saudi Med J. 2008;29(10):1423-1427.

24. Ni WQ, Liu XL, Zhuo ZP, et al. Serum lipids and associated factors of dyslipidemia in the adult population in Shenzhen. Lipids Health Dis. 2015;14:71.

25. Ambachew H, Shimelis T, Lemma K. Dyslipidemia among diabetic patients in Southern Ethiopia: Cross-sectional study. J Diabetes Endocrinol. 2015;6(4):19-24.
Diabetes, Metabolic Syndrome and Obesity: Targets and Therapy is an international, peer-reviewed open-access journal committed to the rapid publication of the latest laboratory and clinical findings in the fields of diabetes, metabolic syndrome and obesity research. Original research, review, case reports, hypothesis formation, expert opinion and commentaries are all considered for publication. The manuscript management system is completely online and includes a very quick and fair peer-review system, which is all easy to use. Visit http://www.dovepress.com/testimonials.php to read real quotes from published authors.

Submit your manuscript here: https://www.dovepress.com/diabetes-metabolic-syndrome-and-obesity-targets-and-therapy-journal 